Vol. 39(2), pp. 246-260, Dec. 2020

ISSN 1821-536X (print)

ISSN 2619-8789 (electronic)
Tanzania Journal of Engineering and Technology

Copyright $@ 2020$ College of Engineering and

Technology, University of Dar es Salaam

Full Length Research Paper

\title{
Wind Power Integration and Its Impact on Power Quality - A Didactic Approach
}

\author{
Santos Kihwele \\ Department of Electrical Engineering, University of Dar es Salaam, Tanzania \\ Corresponding Author: kihwele2002@yahoo.com
}

\begin{abstract}
This paper presents a model of a wind power system integrated with realistic power system, with intention of using it in addressing power quality issues in relations to grid codes during steady-state operation transient-state operation i.e., presence of grid fault events. For that case, a didactic approach of the normal performance of power systems due to the connection of fixed-speed wind turbine with induction generators is used. A study of integrating wind farms will be presented, including the incidence of high inrush current due to switching capacitor banks, out-rush current and voltage sags due to nearby three phase faults. As mandatory for the grid codes regulation, the incidence on the power quality at the point of common coupling is analyzed too. As a result of the contingency study, it will be shown that capacitors bank and fault current limiter can help the wind farm to ride-through a fault.
\end{abstract}

Keywords: Capacitor bank, fault current limiter, fault ride-through, Grid codes, Inrush current, Out-rush current, Power quality, Voltage sag, Wind farm, and Wind turbine.

\section{INTRODUCTION}

Recently, there is a shift in trend from installing few wind turbines with small capacity to planning to install many and large wind farms with rated capacity in MW class (Muljadi et al., 2006; Liang, 2017; Ivan et al., 2014). This increased penetration makes the power network more dependent and vulnerable to the impact of large penetration of wind power generation. Such situation prompt to say that, in future wind farms must be able to act like conventional power plants and hence should be active controllable units in the grid network. Another consequence of the increased grid tied wind farms in the near future is that the wind farms will directly be connected to the high voltage AC (HVAC) or DC (HVDC) power transmission line (Hansen et al., 2001; Liu and Li, 2020; Mohammadi et al., 2018). Many countries in the world are developing or modifying interconnection rules and processes for wind power through a grid code, i.e., the Nordel grid codes have adopted the ride through profile shown in Figure 1 for recommendation in the Nordic countries (Molinas et al., 2008), because the grid codes have identified many potential adverse impacts of large-scale integration of wind resources. i.e., Wind farms using squirrel cage induction generators (SCIG) 
directly connected to the network will most acutely suffer from the new demands (Molinas et al., 2008), since they have no direct electrical control of torque or speed, and would usually disconnect from the power system when there is grid fault or voltage drops of more than 10-20\% below rated value (Molinas et al., 2008).

A special focus in grid codes requirements is drawn in such a way that the wind turbines must be able to remain connected to the grid during and after network faults i.e., wind turbine should have Fault-RideThrough (FRT) capability and may have to adjust its reactive power consumption or production in order to control the voltage at the point of common coupling (PCC). Therefore, the utilities responsible for power supply networks must follow the requirements of the grid codes that provide proper technical know-how on the influence of wind power integrated in power system in relation to power quality and enhanced controllability of power system with wind turbines.

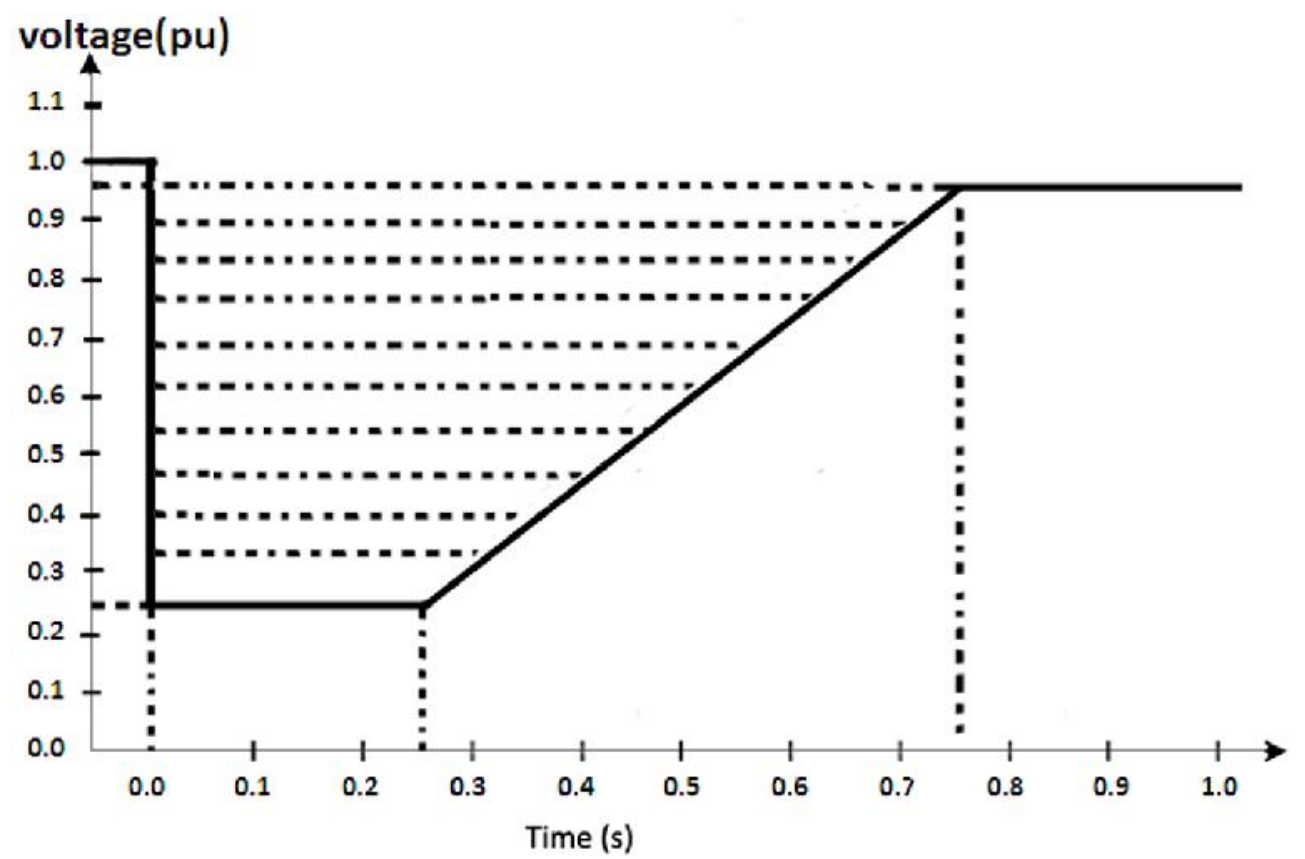

Figure 1: Ride through profile from the Nordel grid codes for the Nordic countries (Molinas et al., 2008)

Having said that, it is now important to analyse and interpret the simulation results obtained from the models under studies that simulate the interaction between wind turbines and a grid network. Such simulation models provide both the wind power developers and the utility operators with the necessary information to perform such as preliminary studies before connecting them to the grid networks. In fact, simulation of wind farm interaction with the grid network under steady-state and transient-state may provide the necessary information that may lead to lowering the overall grid connection costs
(Hansen et al., 2002). More importantly, such model can be used to even further extend study on different aspects such as that of synchronization of wind farms to the grid networks, control strategies, connection to weak grids, and to HVAC/DC connections.

Therefore, this paper presents the main result findings obtained from a wind farm integrated with realistic power system model capable of simulating the interaction between them, both during steady-state and during transient-state operations. Due to ever-increasing wind 
power penetration into power networks, it has necessary to have detailed study and communicate the findings which is the motivation of this study. A power system computer aided design/electromagnetic transient including DC (PSCAD/EMTDC) Simulation software is used to carry out modeling and simulation of the system under study. The study for this research is on the installed $15 \mathrm{MW}$ wind farm, which consists of ten fixed speed wind turbines each of 1.5 MW rated power. This case study establishes the first steps by considering small scale toward the largescale case study, i.e., a $150 \mathrm{MW}$ wind farm connected to the transmission network.

The system under study consists of a grid model with ten wind turbines as follows:

- the grid network includes the major electric components in the wind farm power collection system and the substation, and uses equivalent electric circuit for the remaining grid.

- the wind turbine includes aerodynamic, mechanical and electrical sub systems which are induction generator, a capacitor bank for reactive power compensation and a step-up transformer.

The rest of the paper is organized as follows. The first part summarizes the grid modeling, wind turbine modeling and its related power quality problems. The second part describes the studied cases, including both during steady-state operation and during transient-state operation i.e., during grid fault events. The last part finishes with the main conclusions.

\section{METHODS AND MATERIALS}

\section{Grid Modelling}

Wind turbines are described with aggregated wind turbine model. In order to reduce the complexity of the analysis, the aggregated wind turbine model will represent a wind farm. This aggregated model of the wind farm must have the same voltage, current and power response at the point of common coupling as those of the individual wind turbines (Marin et al., 2004). The normalized (per unit) parameters of the aggregated model are the same as that of an individual induction generator, but the rated power is the sum of the whole group of induction generators.

Wind farm consists of 10 wind turbines each of 1.5 MW rated capacity with fixedspeed stall-regulated model. The wind farm is connected to the substation which consists of 10 MVA $0.69 / 34.5 \mathrm{kV}-\mathrm{Y}$ grounded transformer with leakage inductance of $10 \%$ located $10 \mathrm{~km}$ away from the installation site. The connection from the wind farm to the substation and the substation itself are modelled by physical components like transformers, line, busbar and load while a simplified Thevenin equivalent circuit is adapted to model the remaining power system with voltage rating of $34.5 \mathrm{kV}$. This is a fair approximation for comparative power quality studies since in this case the grid is very strong compared to the installed capacity of the wind farm. In this case, the loads are connected directly to the $0.69 \mathrm{kV}$ side and $34.4 \mathrm{kV}$ side and are modeled as constant load as indicated in Figure 2. Load is included due to the reason stated in (Duggan, 2006).

\section{Wind Turbine Modelling}

For this study, a wind turbine model of a fixed-speed has been developed, it operates at constant speed. That means that, regardless of the wind speed, the wind turbine rotor speed is fixed. Also have the advantage of being simple, robust, reliable, inexpensive electric systems and well proven operations. The model includes wind speed, the aerodynamic, the mechanical, electrical wind turbine components, namely 
induction generator and capacitor bank for reactive power compensation with an overall control system model. Figure 3, illustrates the overall structure of the model

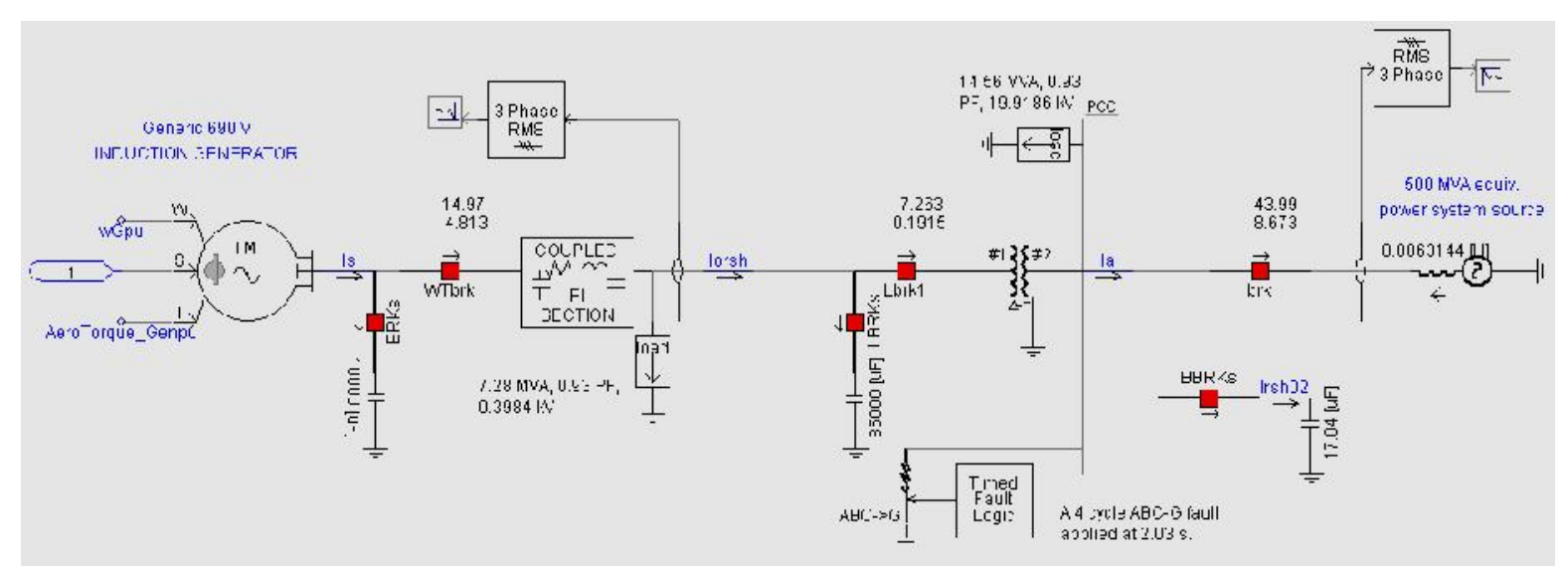

Figure 2: Grid-connected wind turbine system

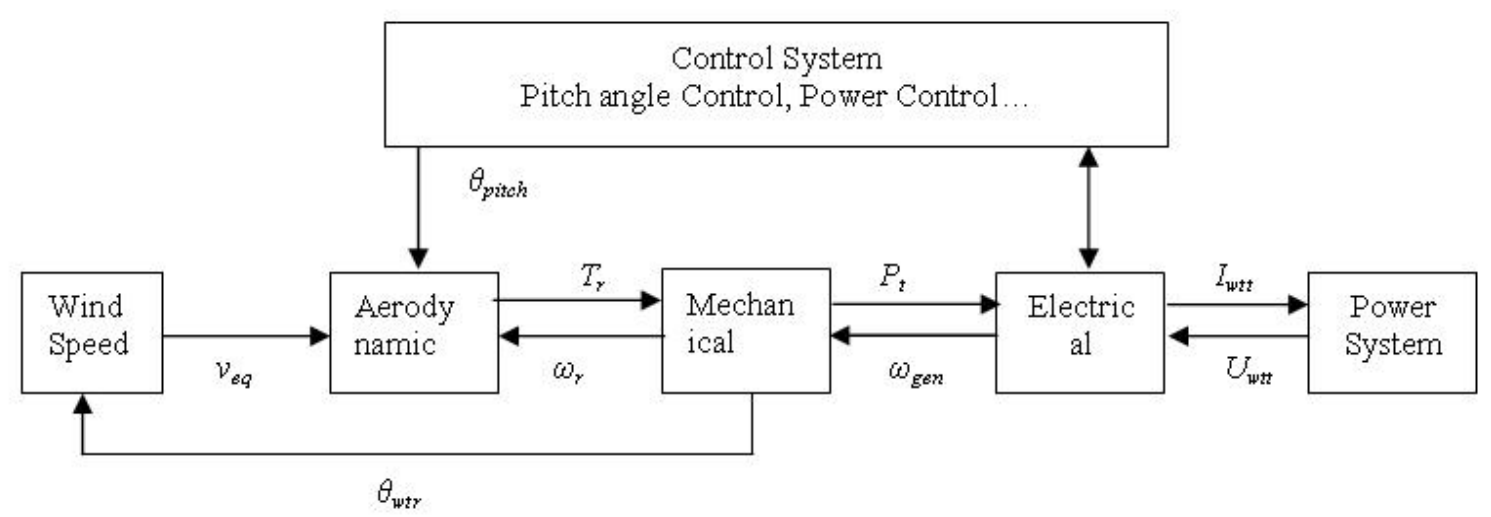

Figure 3: General structure of the wind turbine model

\section{Wind Model}

Wind speed is calculated as the sum of four components, namely: a steady speed (base speed), a ramp, a gust and a random component.

\section{Aerodynamic Model}

The aerodynamic power developed on the main shaft of a wind turbine with rotor radius $R$ at a wind speed $v_{e q}$ and air density $\rho$ is modelled by the well-known relation as in equation (1).

$$
p_{r}=\frac{1}{2} \rho \pi R^{2} v_{e q}^{3} C_{p}\left(\theta_{p i t c h}, \lambda\right)
$$

Where the aerodynamic efficiency $C_{p}=$ $C_{p}\left(\theta_{\text {pitch }}, \lambda\right)$ is depending on the blade angle $\theta_{\text {pitch }}$ and on the tip speed ratio $\lambda=R \omega_{r} d$ $v_{e q}$, where, $\omega_{r}$ is the rotational speed.

The aerodynamic torque, $T_{r}$ is linked to the aerodynamic power according to equation (2).

$T_{r}=\frac{P_{r}}{\omega_{r}}=\frac{\pi}{2 \lambda} \rho R^{2} \mathcal{V}_{e q}^{2} C_{p}\left(\theta_{\text {pitch },} \lambda\right)$ 


\section{Mechanical Model}

The mechanical transmission system (low speed shaft, gear box, coupling, high speed shaft) has been considered as a single coupling between the wind turbine and the induction generator.

\section{Induction Generator}

The squirrel cage induction generator (SCIG) model is used in this study. The SCIGs are common type found in wind energy applications. Due to bring mechanically simple with high efficiency and low maintenance cost, they are preferred compared to other type of induction generator. More importantly, SCIG based WTs are very robust and stable, however one of their major weakness is the fact that there is a close and unique relationship between active power $(\mathrm{P})$, reactive power $(\mathrm{Q})$, terminal voltage $(\mathrm{V})$ and rotor speed (Munteanu et $a l ., 2008)$. This indicates that, any increase in the active power production will depend on an increase in the reactive power consumption. In that way, it leads to a relatively low full-load power factor. Hence, in order to control the reactive power absorption from the grid, SCIGs are usually equipped with capacitor banks for power factor correction.

\section{Capacitor Bank}

In fixed speed induction generators, controlled capacitor banks are used to offset the reactive power drawn by the induction machine when the generator is connected to the systems. These capacitor banks can be either mechanically switched using contactors or electronically switched using thyristors (Santoso, 2009). Since the amount of reactive power consumption varies significantly over time, capacitor banks are frequently switched. Achieve the switching mechanism, zero voltage and zero current crossings are used in switching the capacitors on and off in order to reduce the switching transients (Santoso, 2009). In this case, the reactive power to be compensated by the capacitor banks can be calculated as in equation (3).

$$
\Delta Q=P\left(\tan \phi_{1}-\tan \phi_{2}\right)
$$

Where $Q$ is the required reactive power, $P$ is the active power, $\varnothing_{1}$ is the initial angle correspond to poor power factor, $\emptyset_{2}$ is the desired angle for improved power factor.

Then the required capacitor size can be calculated as in equation (4).

$$
C=\frac{\Delta Q}{2 \pi f k V_{L L}^{2}}
$$

where $C$ is the capacitance, $f$ is the frequency and $k V_{L L}^{2}$ is the line-to-line voltages.

\section{POWER QUALITY PROBLEMS}

There are different ways of defining a power quality problem. In this paper a power quality problem can be defined as a deviation from the ideal (sinusoidal, constant magnitude) voltage or current (Bollen et al., 2010). Since a wind turbine is designed to supply real power to the grid network. A reactive power exchange between the wind turbine and the grid depends on the type of the wind turbine; it can be consumed, produced or no reactive power can be exchanged with the grid (Petru, 2001). As a consequence of this fact, the voltage at the point of common connection, $U_{P C C}$, is influenced. This is demonstrated in Figure 4, and is described in equation (5).

$U_{P C C}=R_{g} \frac{p}{U_{N}}+X_{g} \frac{q}{U_{N}}+U_{N} \ldots \ldots \ldots$

where $U_{N}$ nominal voltage of the grid; $U_{P C C}$ voltage at the point of common connection (PCC), $p$ active power produced, $q$ reactive power consumed, $R_{g}$ grid resistance, and $X_{g}$ grid reactance. 
Higher active power production is followed by an increase in the voltage drop over the grid resistance and a consequent decrease in the voltage $\mathrm{U}_{\mathrm{PCC}}$. More consumed reactive power causes on the contrary an increase in the voltage drop over the grid reactance and a corresponding decrease in the voltage $\mathrm{U}_{\mathrm{PCC}}$, i.e., voltage sags during the grid faults. A power quality evaluation of a wind turbine is addressed for two different operational modes. First, it is investigated under normal operation and switching transients originating in the switching of a capacitor bank and Secondly, the impact on the grid when a three-phase fault happens.

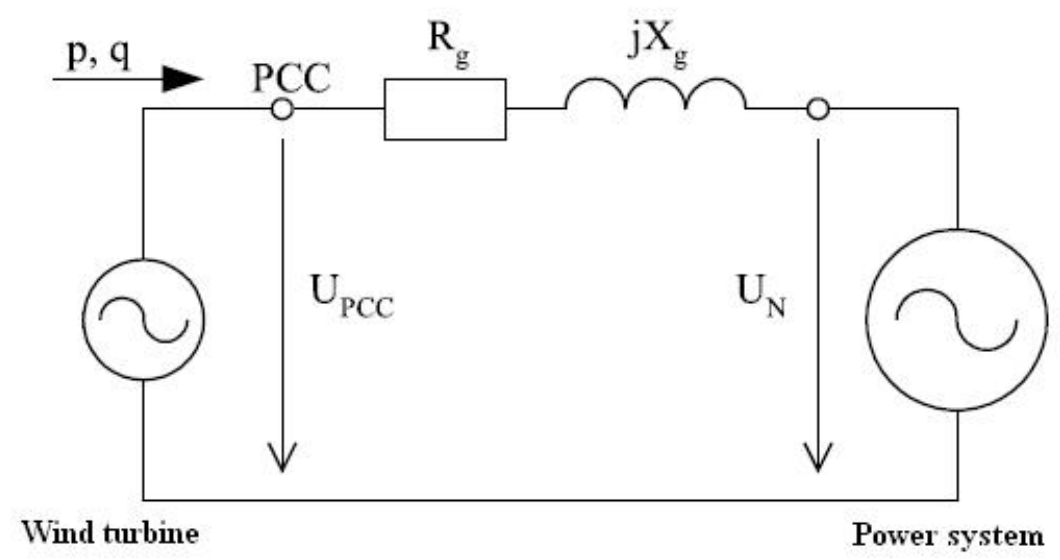

\section{Figure 4: Connection of a wind turbine to the grid}

\section{Capacitor Switching Inrush and Outrush Currents}

Capacitive current switching duties during capacitor energizing or close in faults near a capacitor can be very severe and exceed the breaker switching duty. Energizing a back-to-back capacitor bank can cause a very high frequency and high magnitude inrush current (Santoso, 2009). When the magnitude and frequency of the inrush current exceed the circuit breaker's capacitive current switching (i.e., inrush) capability, the breaker may not close successfully. In addition, the inrush current as in (6), may cause false operation of protective relays and excessive voltages for current transformers in the neutral line or affected phase of grounded-wye capacitor banks. Under such condition, the so-called inrush current limiting reactors can be used to limit the capacitive switching transient duties (McCauley et al., 1980). This method is usually preferred since it can limit inrush currents during switch restrikes as well. The minimum size of limiting reactors can be determined based on frequency or peak current requirements as in equations (7) and (8), respectively.

$$
\begin{aligned}
& I_{\text {inrush }}=V_{m} \sqrt{\frac{C_{s r}}{L_{s r}}} \ldots \ldots \ldots \ldots \ldots . . . . \\
& L_{i n} \geq \frac{1}{2}\left[\frac{1}{\left(2 \pi f_{\text {in }}^{\text {rated }}\right)^{2} C_{s r}}-L_{s r}\right] . \\
& L_{\text {in }} \geq \frac{1}{2}\left[\left(\frac{V_{m}}{I_{p k_{\text {in }}}^{\text {rated }}}\right)^{2} C_{s r}-L_{s r}\right]
\end{aligned}
$$

where $V_{m}$ is the peak voltage, $I_{P k_{i n}}^{\text {rated }}$ is the rated peak inrush current, $f_{\text {in }}^{\text {rated }}$ is the rated peak frequency, $C_{\text {sr }}$ is the series equivalent of the two capacitors and $L_{\mathrm{sr}}$ is the total inductance between the two capacitor banks.

The outrush current is usually very high in magnitude and frequency for a close-in or bus fault (Santoso, 2009). The capacitive 
outrush current duty may exceed the breaker capacitive current switching capability causing delayed fault clearing, damage to other nearby power apparatus and high voltage sags. The outrush current-limiting reactor are used to mitigate the outrush current which are calculated as in equation (9).

$$
L_{\text {out }} \geq \frac{V_{m}}{2 \pi\left(2 * 10^{7}\right)}
$$

To assess the interaction between the wind farms and the power system, typical case studies /scenarios are studied as shown in case studies.

\section{CASE STUDIES}

In the following, a set of simulations are carried out in order to illustrate and evaluate the interaction, both during steady-state operation and transient-state operation with grid fault events, between a large wind farm and a realistic power system model. The goal of these simulations is to illustrate how the wind farm integrations in power system can operates during: i) steady-state operation and ii) transient-state operation i.e., when there is a fault in the grid network.

\section{Case 1: Reactive Power Compensation}

This operating scenario demonstrates the simplified study on wind power system with induction generator (WPS-IG) when started, it is found that, at rated wind speed of $14 \mathrm{~m} / \mathrm{s}$, the real power output (i.e., $P_{o}$ ) from the wind farm is $15.08 \mathrm{MW}$ while reactive power output (i.e., $Q_{o}$ ) is 6.74 MVAr. This means that the WPS-IG is operated at the power factor (p.f.) of 0.91 and the voltage at the sending end (i.e., $V_{s}$ ) is 0.94 p.u. In practice, it is usually required that a wind turbine is operated at the p.f. $=0.95$ or higher (Santoso, and Le, 2006). The simplest way to achieve this is using a no-load capacitor bank to compensate for the reactive power demand at the terminals of WPS-IG. Determination of the required capacitor size for $p . f$. $=$ 0.95 operation is straight forward as indicated by equations (3) and (4). With 1.783 MVAr capacitor bank online during starting the reactive power injected into the wind turbine generator is reduced from $Q_{\text {inject }}=6.74$ to $Q_{\text {inject }}=5.038 \mathrm{MVAr}$. Note that, the wind turbine output power is 15 MW and reactive power output is 5.038 MVAr hence the desired p.f. $=0.95$ is achieved, with the $\mathrm{v} V_{s}$ profile is slightly improved to 0.95 p.u. compared to when $Q_{\text {inject }}=0.0$ MVAr. The results validate the agreement between the calculation and simulation for power factor correction. They also show the correct behaviour of the wind-turbine connected power system.

\section{Case 2: Wind Power Integration and Switching Transients}

This case demonstrates the response of a simplified study of wind power integration into the grid with respect to voltage regulation and the effect of switching transients. The analysis begins with a 7.28 MVA, 0.93 p. $f$. with load connected at $0.69 \mathrm{kV}$ at a $10 \mathrm{~km}$ away from the wind power system location and another load of 14.56 MVA, 0.93 p.f. being connected at $34.5 \mathrm{kV}$. Figure 5 and Figure 6, shows the voltage profile of $0.83 \mathrm{pu}$ at the sending end and $0.93 \mathrm{pu}$ at the common coupling point which are all below the allowed value of $\pm 5 \%$ when these loads are connected. These voltage drops alleviated using a switching capacitor bank which is introduced to compensate for the required reactive power. In the first stage we set the desired p.f. $=0.96$ at the $0.69 \mathrm{kV}$ side in order to improve the voltage at sending end, of which 15.25 MVAr reactive power was supplied at that point, and the second stage we set the desired p.f. $=0.98$ at the $34.5 \mathrm{kV}$ side in order to improve the voltage at the point of common coupling of which 7.65 MVAr reactive power was supplied. From Figure 7 and Figure 8, it is observed that when switching on those two capacitors bank the voltage was improved 
to 0.96 p.u. and 0.98 p.u. at respectively points. However, with the back-to-back capacitor connections a high inrush current of $0.8 \mathrm{kA}$ ( $75 \%$ increase) was observed as seen in Figure 9, and calculated in equation (6). Under such condition the so- called inrush current limiting reactors are determined based on frequency or peak current requirements as in equations (8) and (9), in which $0.168 \mathrm{mH}$ inrush limiting reactor is installed to reduce the inrush current by $61.7 \%$.

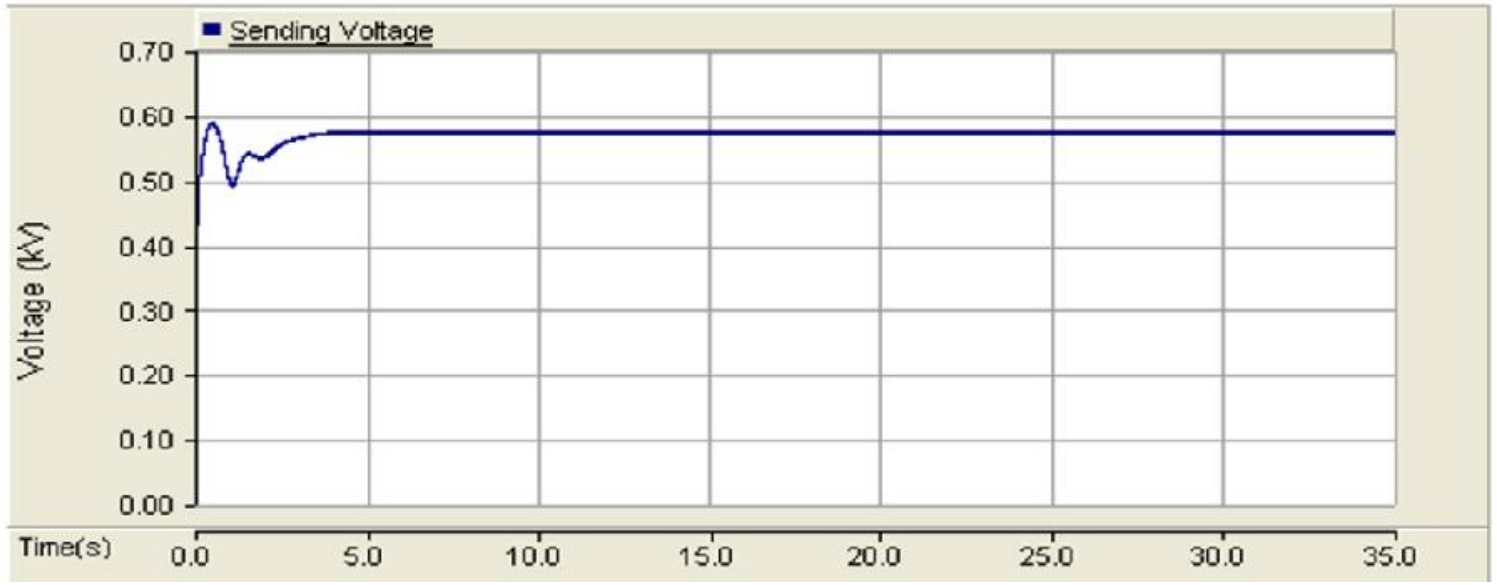

Figure 5: Voltage profile at the sending point when the loads are connected

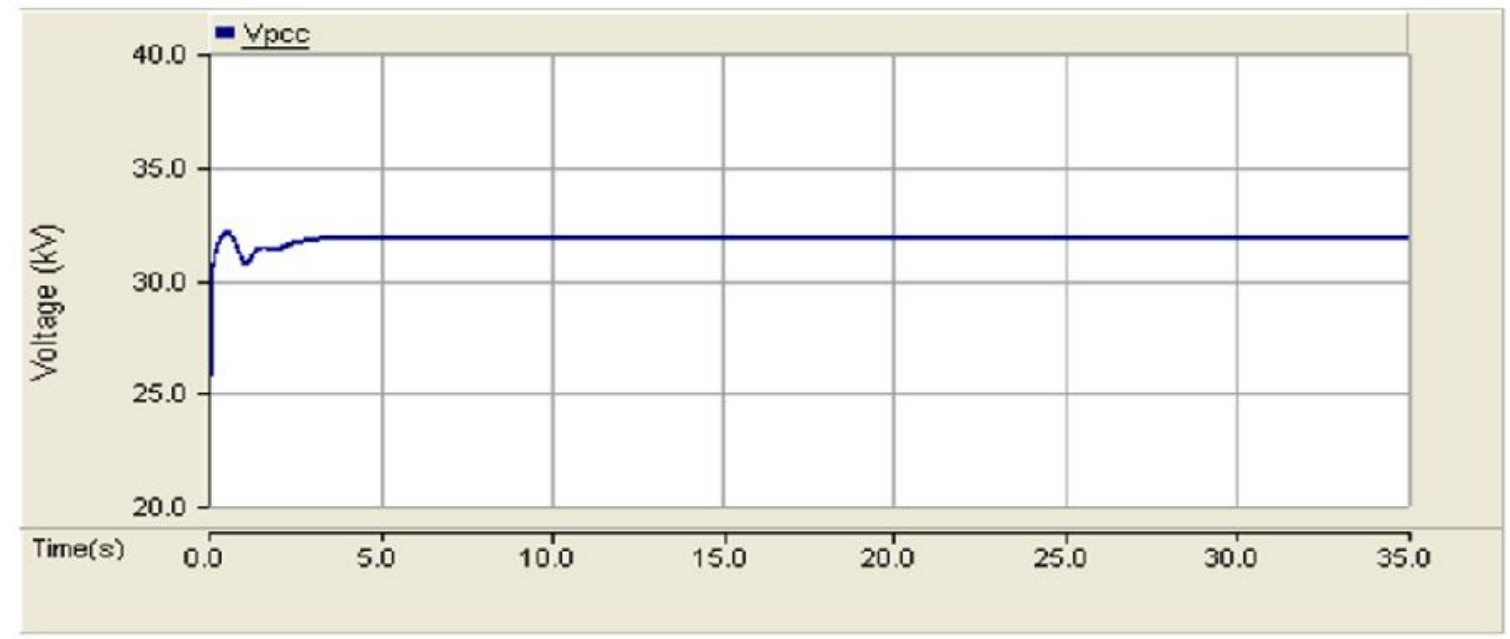

Figure 6: Voltage profile at the point of common coupling when the loads are connected 


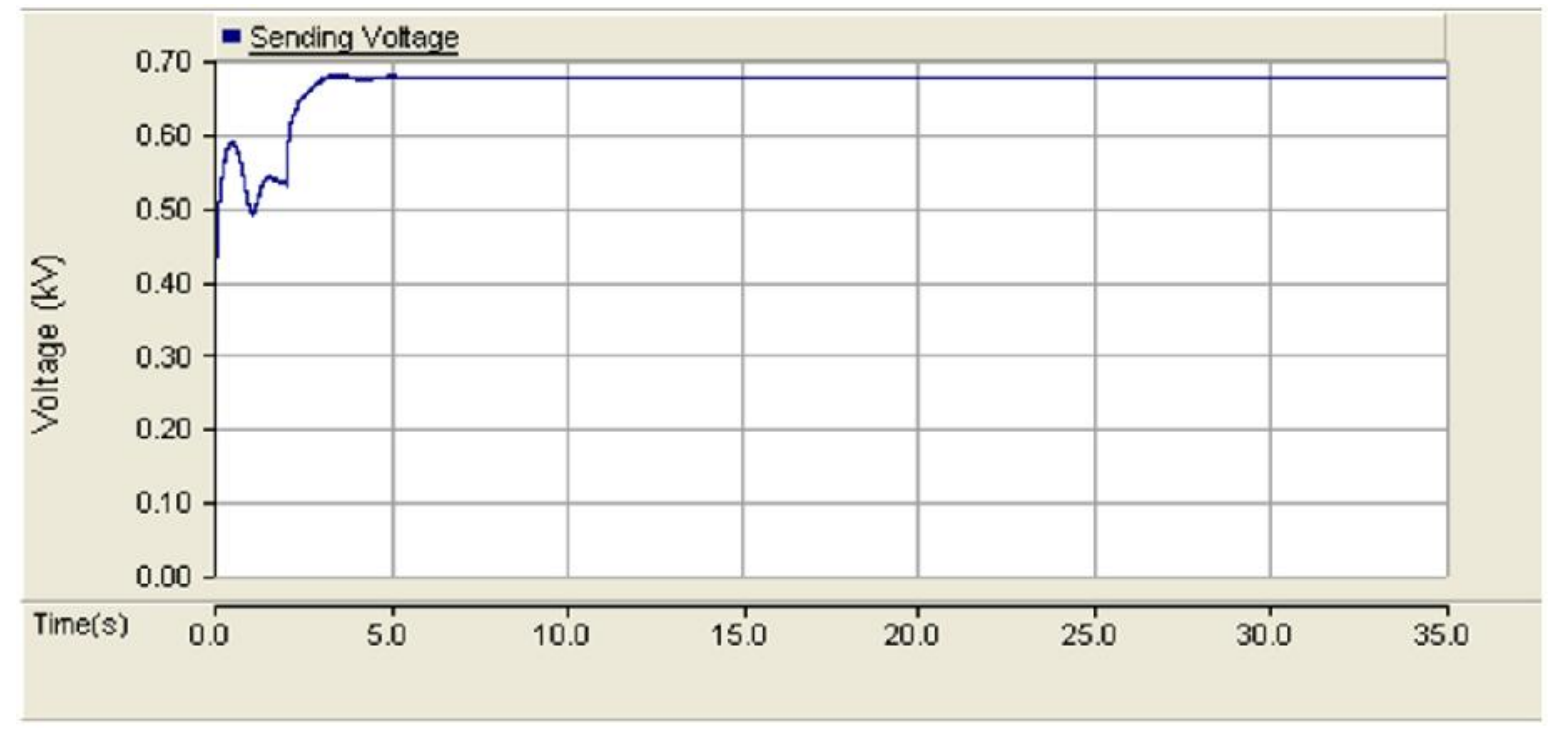

Figure 7: Voltage profile at the sending point when the capacitor banks are switched on

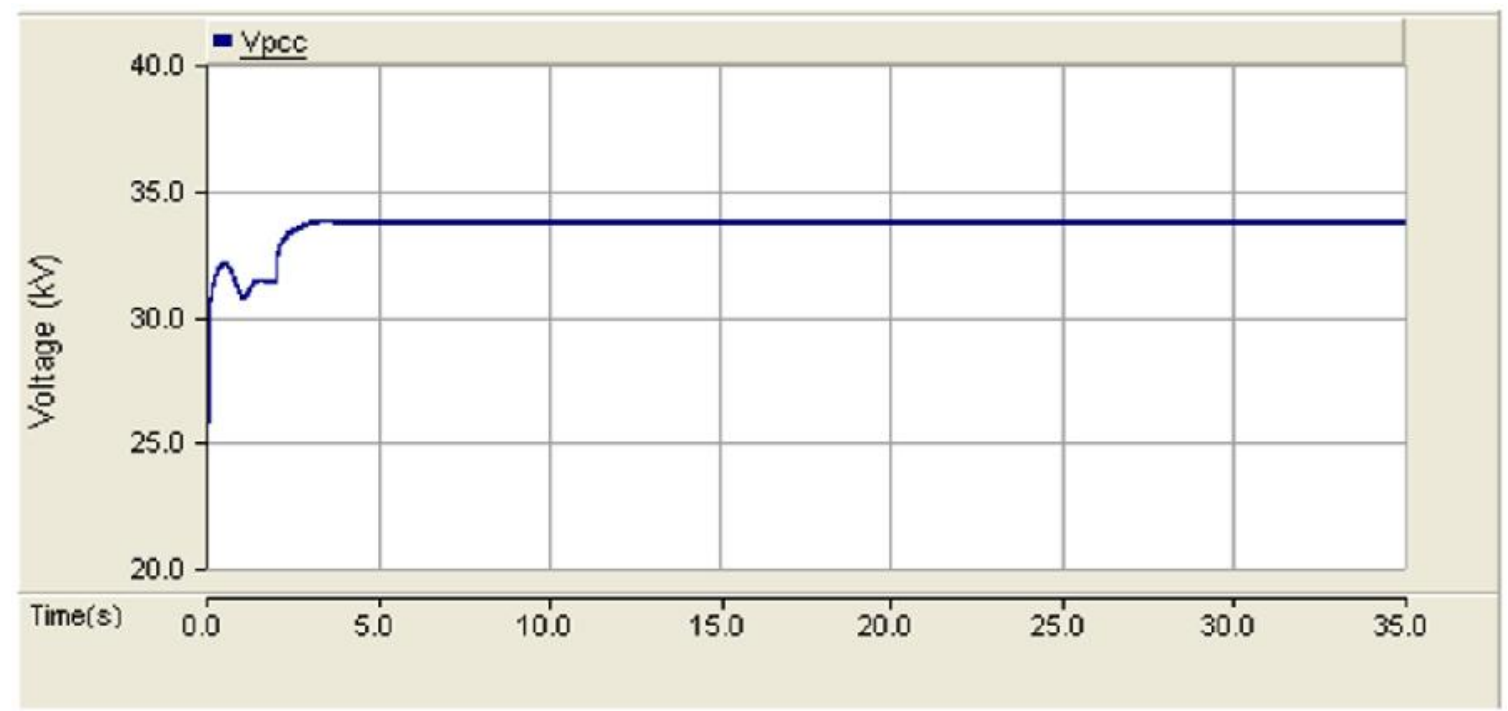

Figure 8: Voltage profile at the point of common coupling when the capacitor banks are switched on 


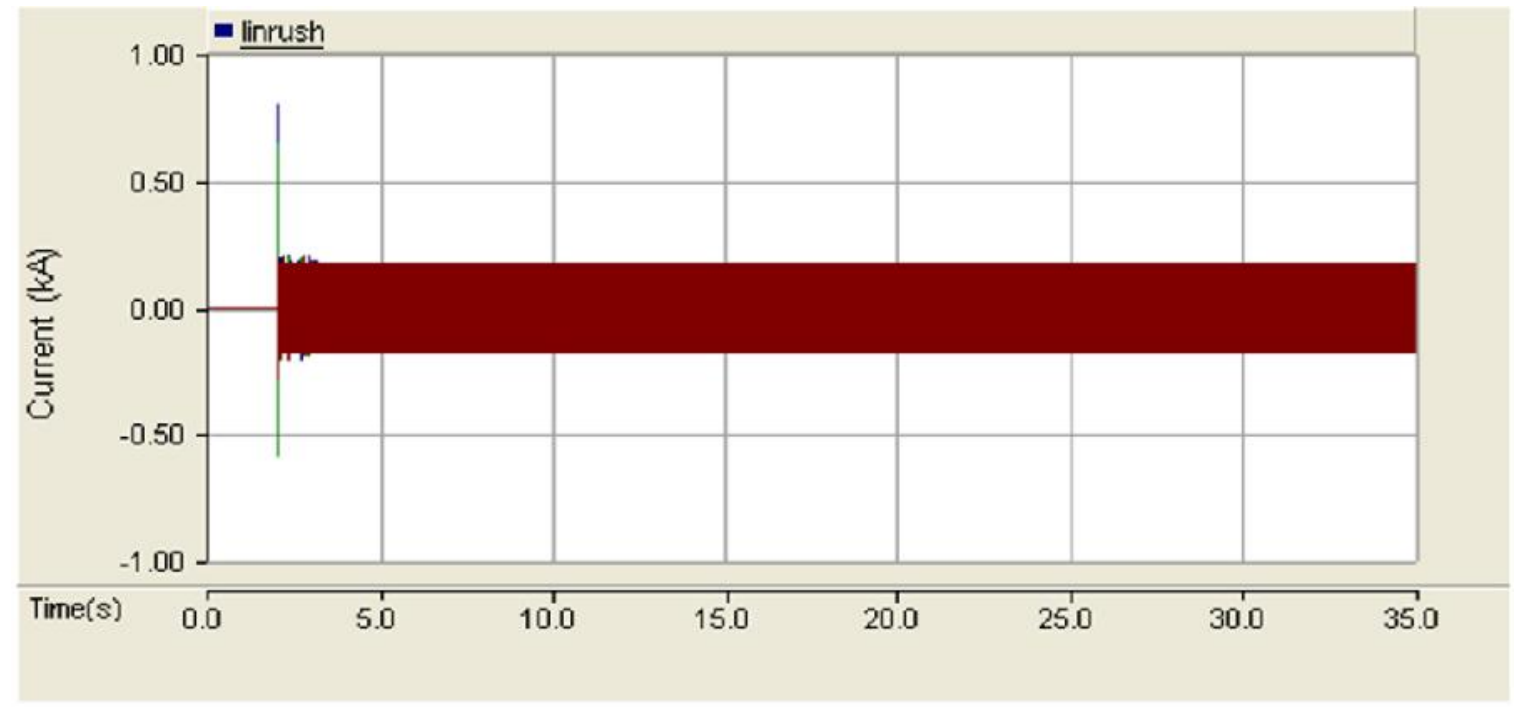

Figure 9: Inrush current due to switching on capacitor banks

\section{Case 3: During and After Grid Fault}

This case demonstrates a 4 cycles three phase fault happening near a capacitor bank at the point of common coupling which resulted into outrush current, as consequences the voltages sag to $0.13 \mathrm{pu}$ at the sending end and 0.13 p.u. at the common coupling point as shown in Figure 10 and Figure 11, respectively. Which are all below the allowed value of low voltage ride through requirements which demands that the wind farm remains connected to the grid for voltage sag to
$0.25 \mathrm{pu}$ (Molinas et al., 2008). Since the loads are still connected while the voltage is below the allowable voltages sag, a stepped decrease in the voltage at the connection node will be noticed as per Figure 10 and Figure 11. This leads to a reduction of the electromechanical torque as seen in Figure 12, and the speed up of wind turbine and the induction generator as shown in Figure 13 and Figure 14, respectively. Final the wind turbine is disconnected due to actuation of the under voltage or over speed protections as seen in Figure 15.

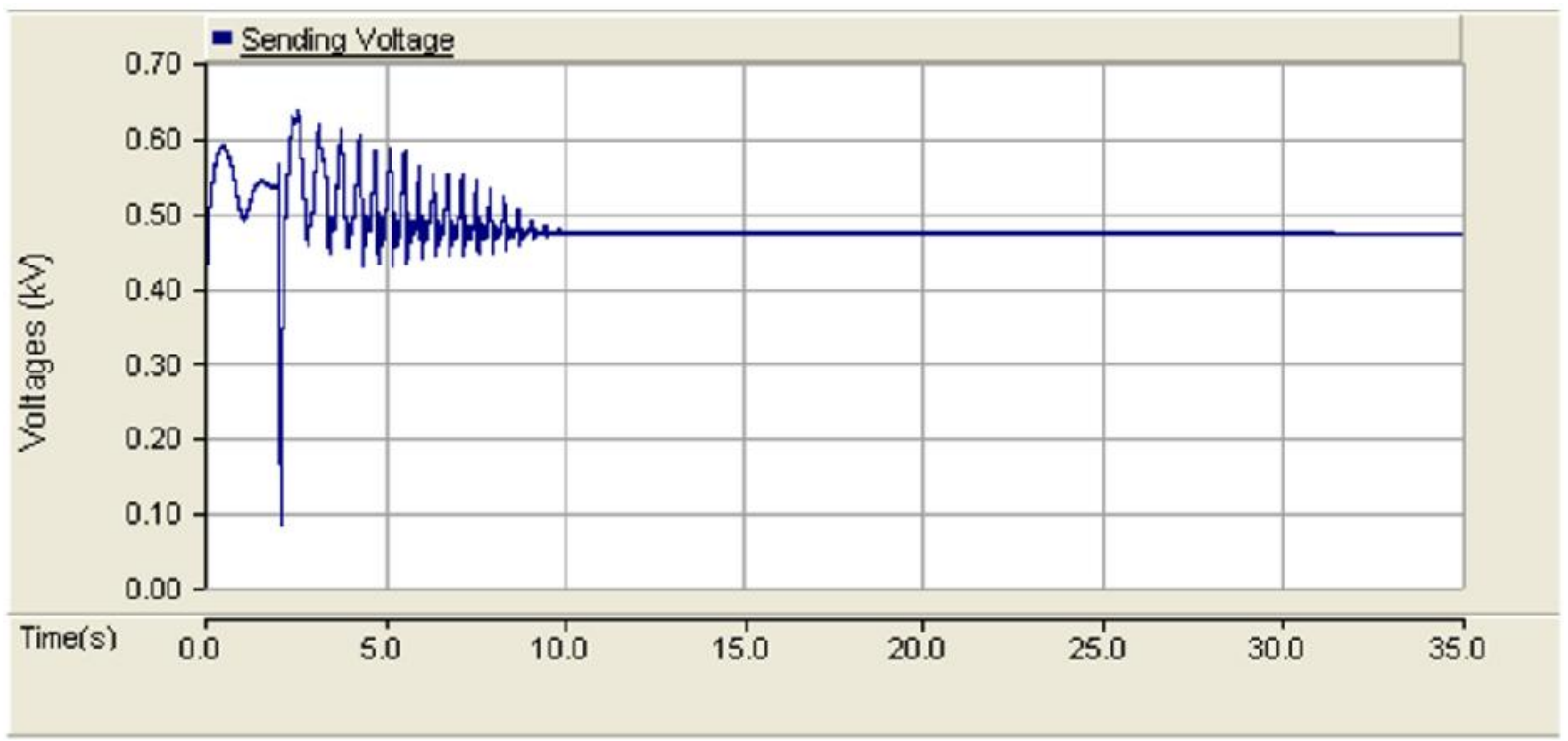

Figure 10: Voltage profile at the sending point when three phase fault happen 


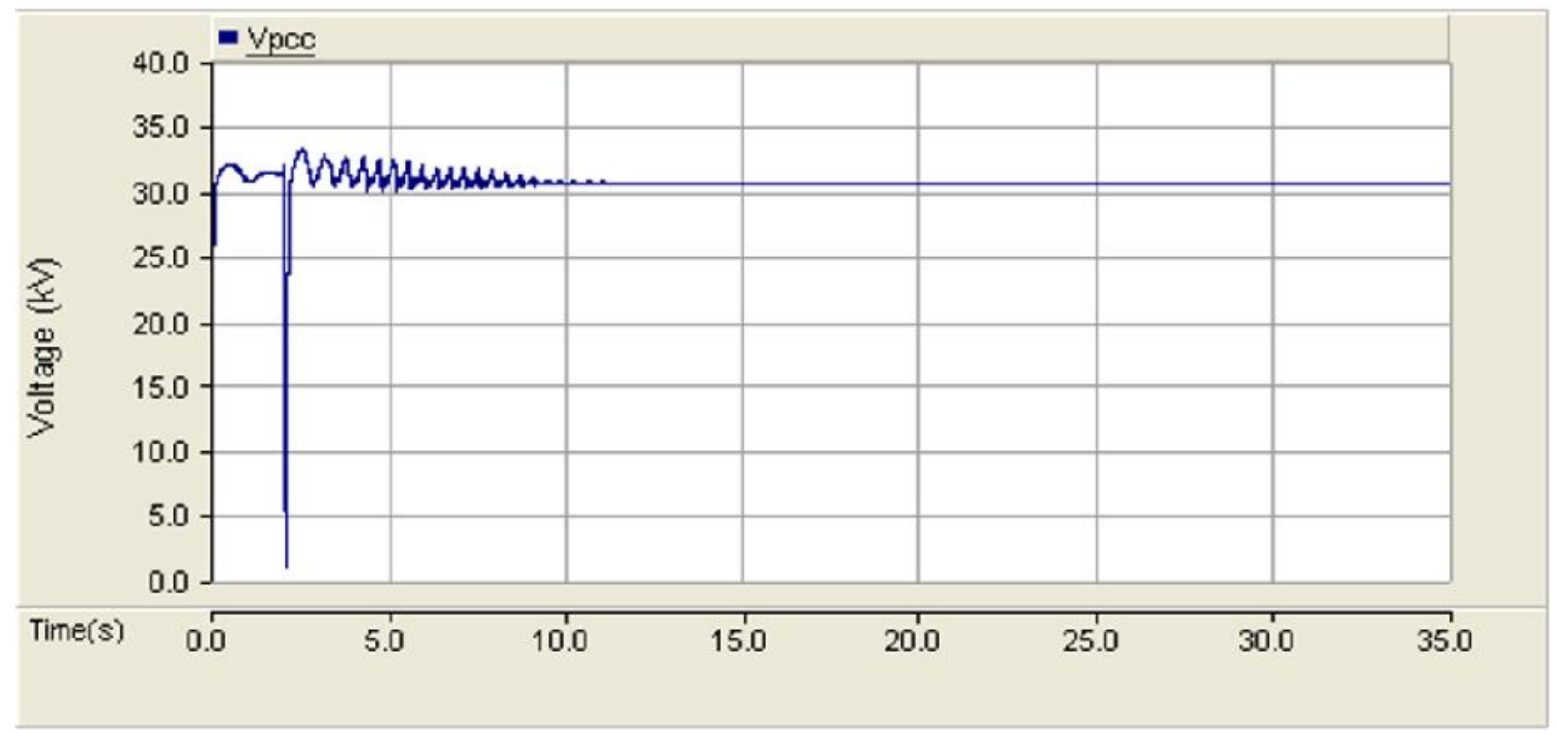

Figure 11: Voltage profile at the point of common coupling when three phase fault happen

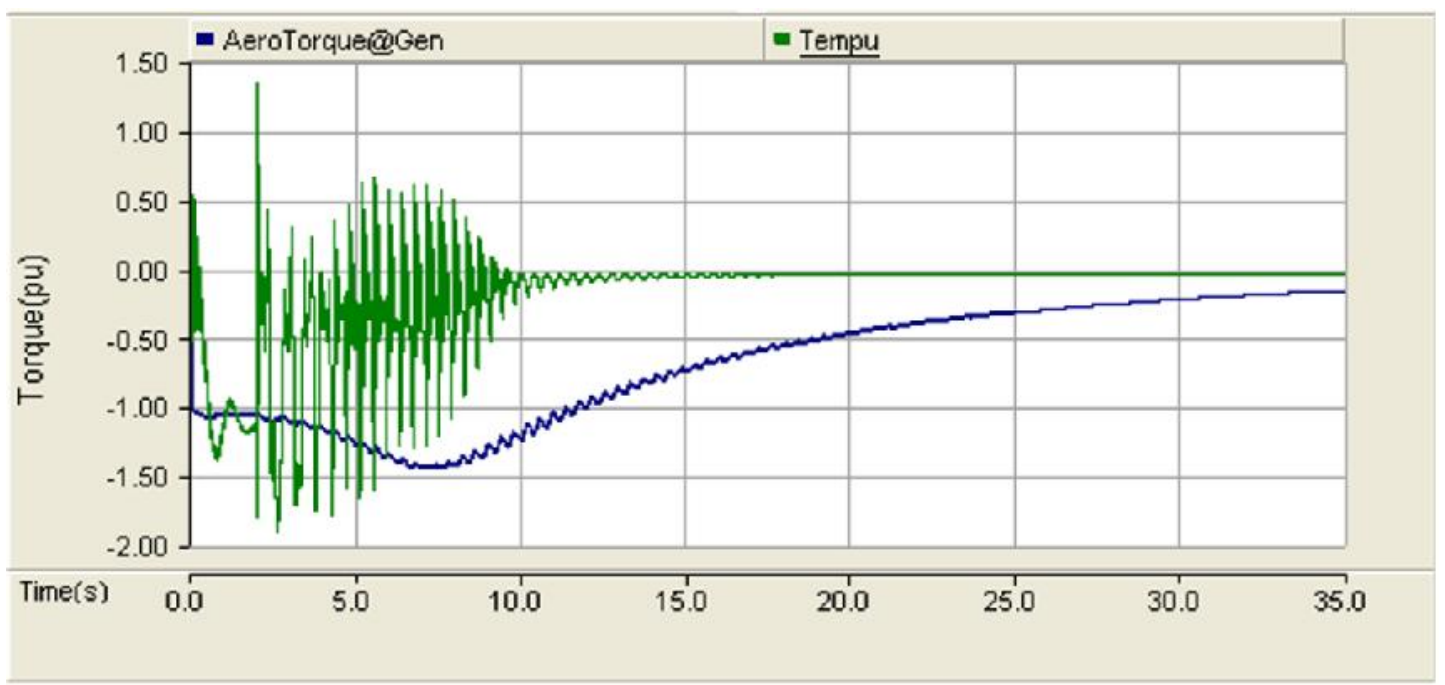

Figure 12: Electromechanical torque when three-phase fault happen 
Wind Power Integration and Its Impact on Power Quality - A Didactic Approach

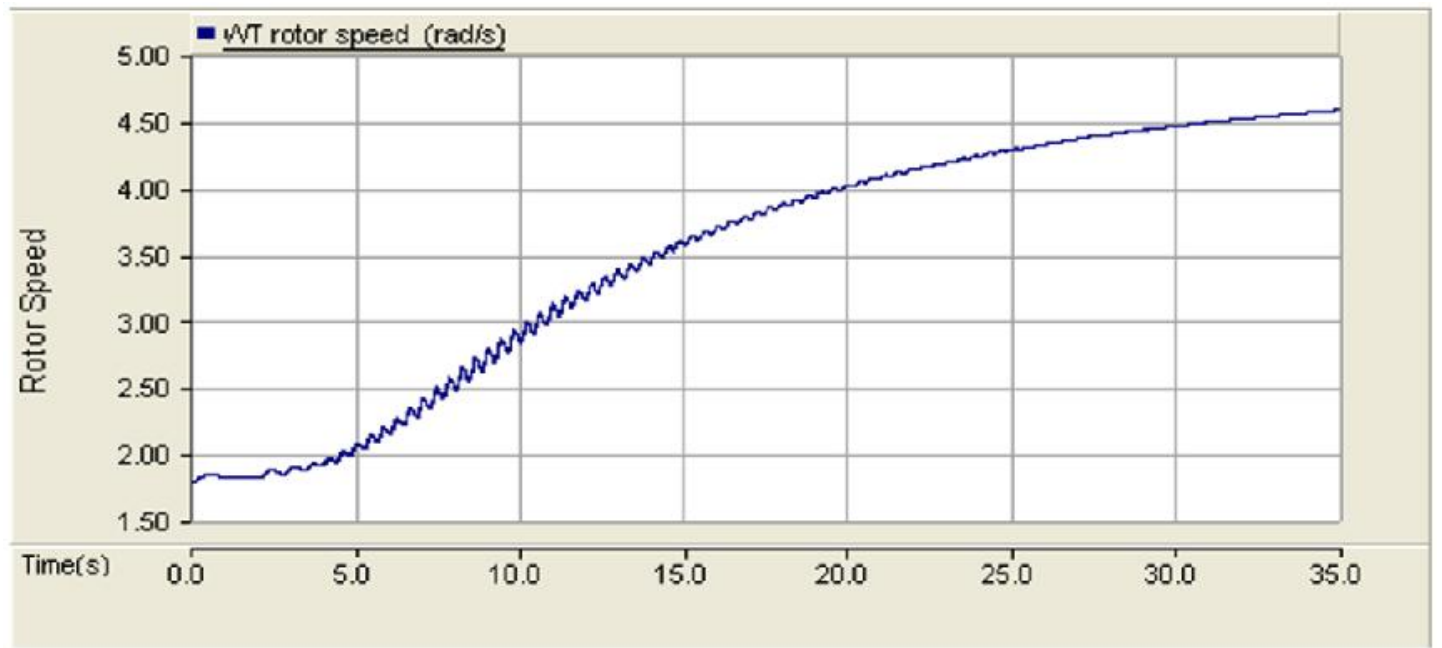

Figure 13: Rotor speed of wind turbine when three-phase fault happen

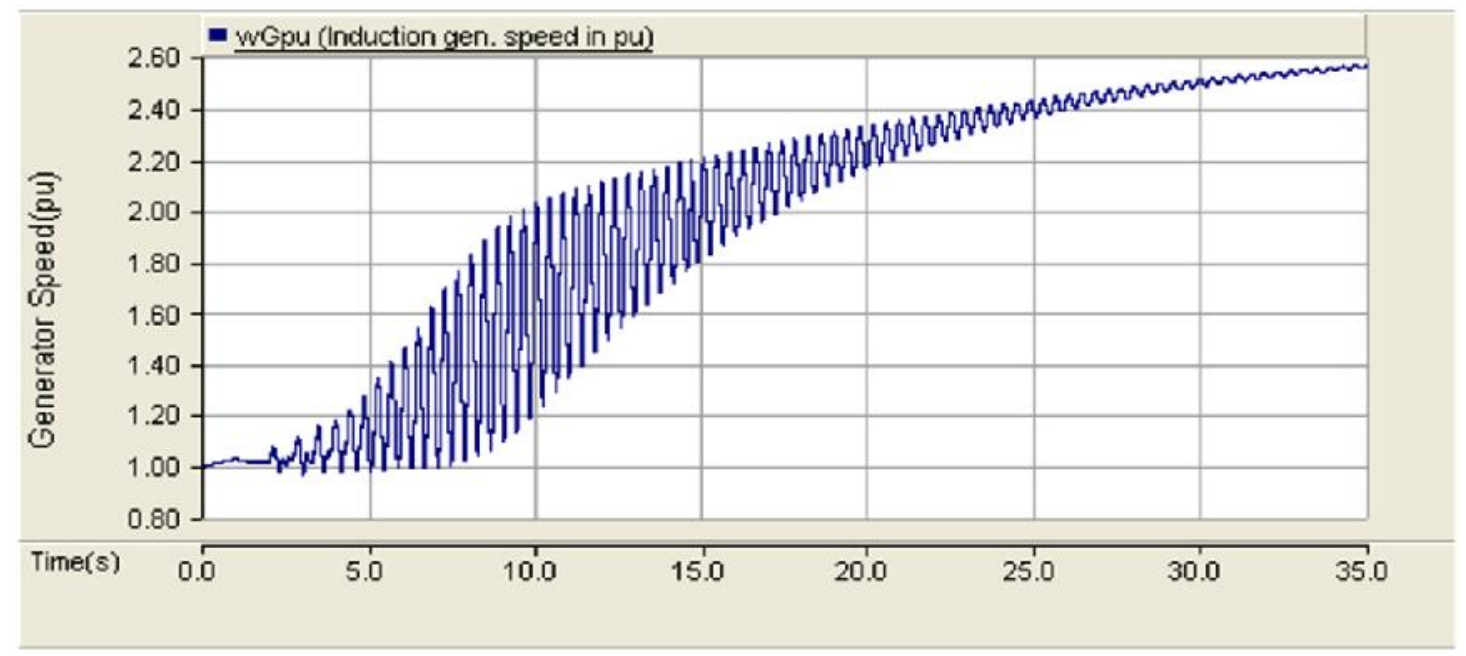

Figure 14: Induction generator speed when three phase fault happen

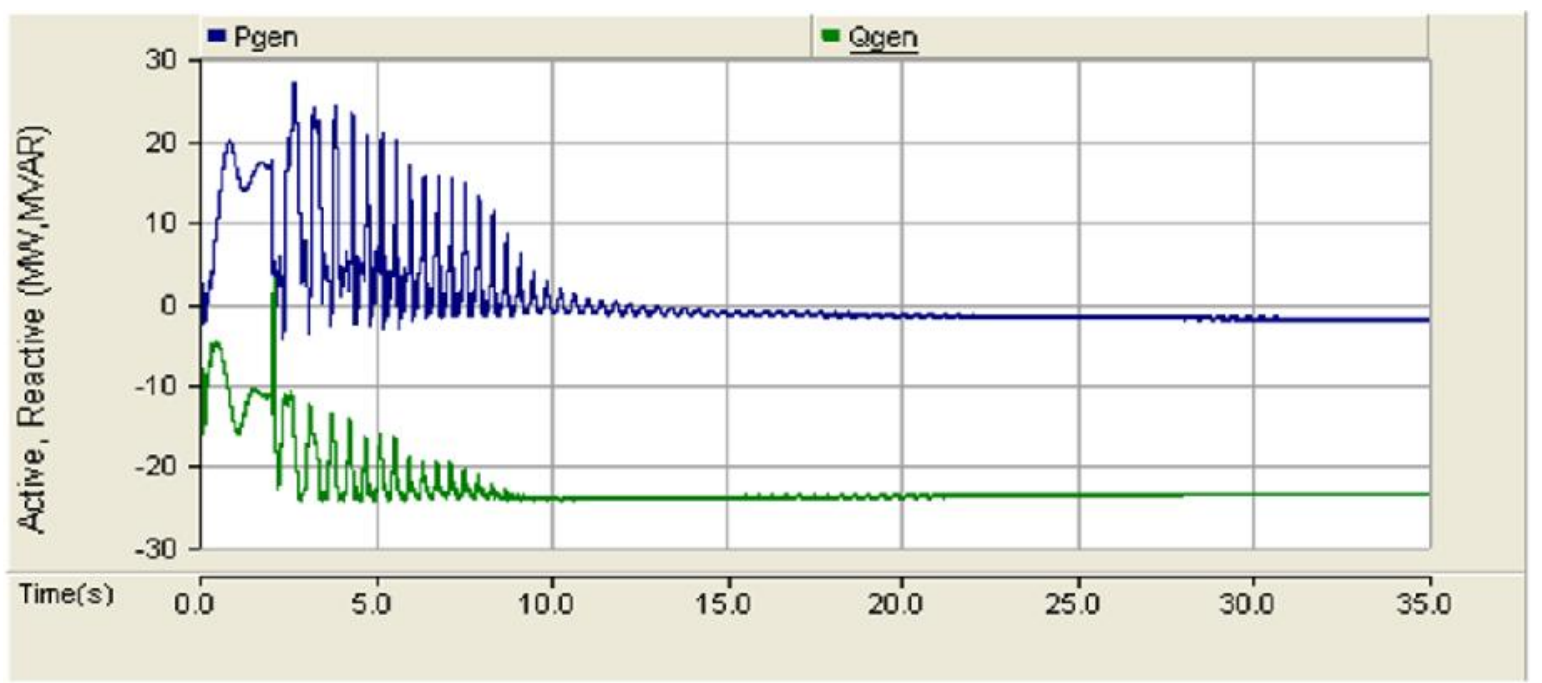

Figure 15: Active and reactive power generated by wind turbines when three-phase fault happen 


\section{Case 4: Fault Ride through Capability}

This case demonstrates the fault ride through of the wind turbines due to the presence of the fault current limiter which is $0.672 \mathrm{mH}$ as calculated in equation (8). The 4 cycles three phase fault happen at the same point with the fault current limiter installed near the faulted area, the voltages this time sag to $0.37 \mathrm{pu}$ at the point of common coupling as shown in Figure 16. This is above the allowed value of low voltage ride through requirements which demands that the wind farm remains connected to the grid for voltage sag to $0.25 \mathrm{pu}$ at the point of common coupling (Molinas et al., 2008). For that case the wind farm was still connected as shown in Figure 17, which proves that the model is fault ride through.

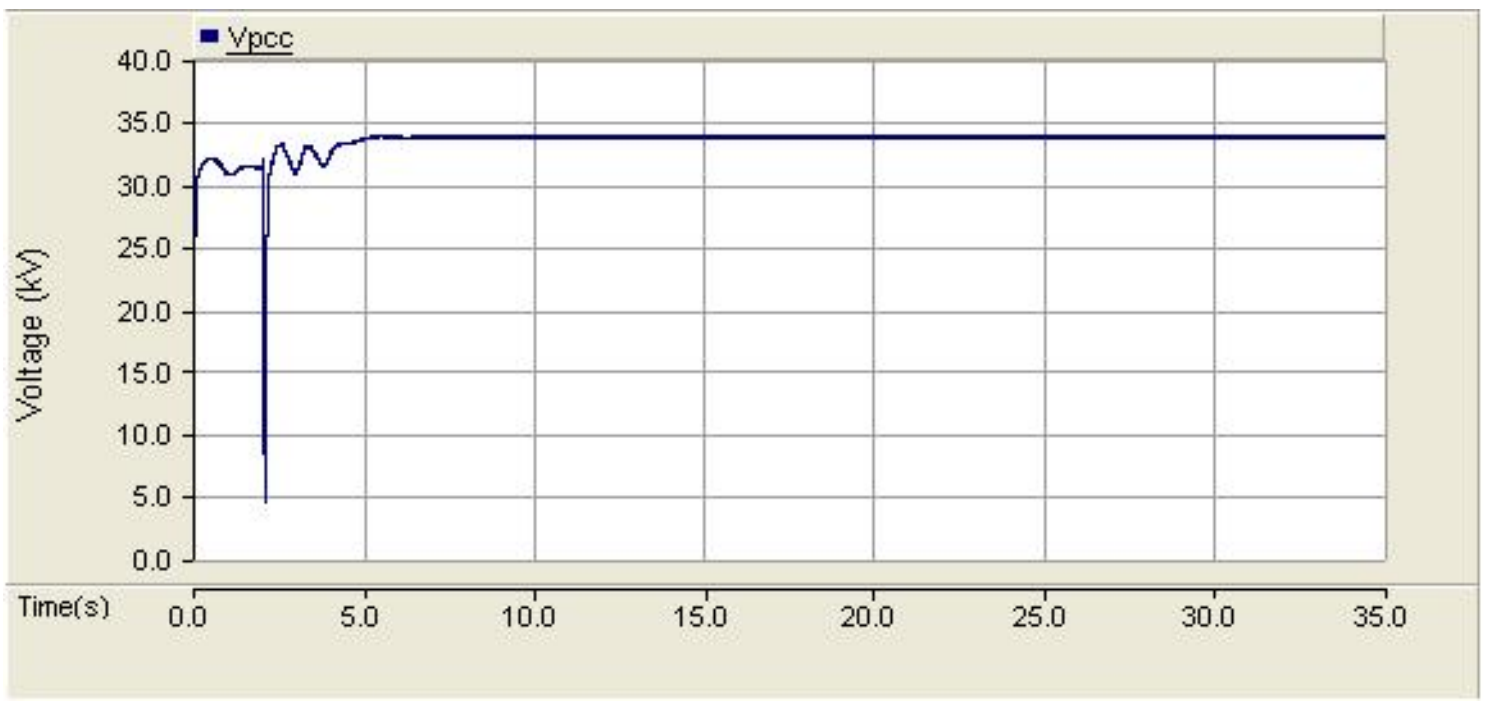

Figure 16: Voltage profile at the point of common coupling when the fault current limiter is installed

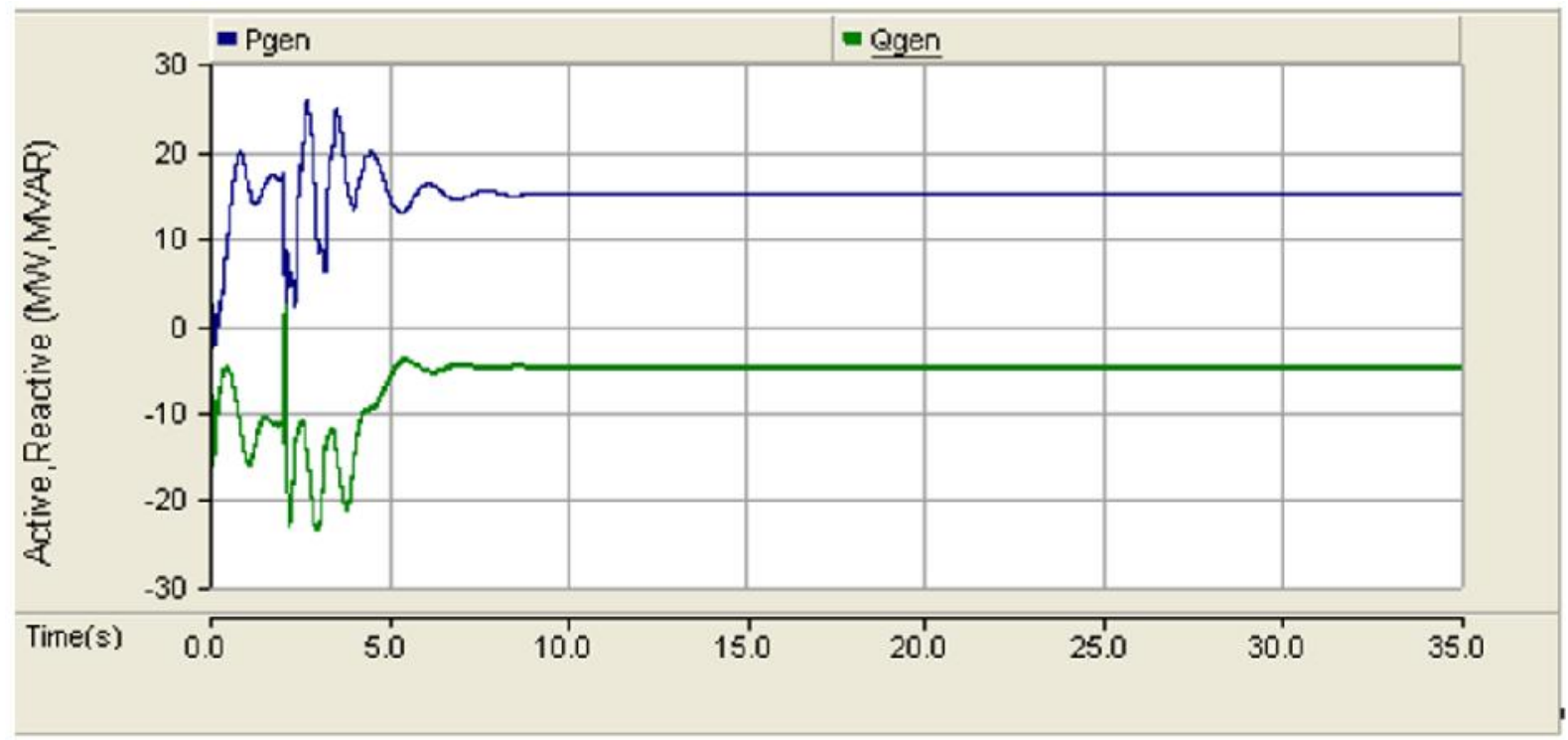

Figure 17: Active and reactive power generated by wind turbines when the fault current limiter is installed 


\section{CONCLUSIONS}

This paper presents a didactic approach of direct-connected fixed-speed wind turbine i.e., SCIG model integrated with realistic power systems. The wind turbine and wind farm models integrated with realistic power systems presented is used to facilitate clear understanding of wind power integration and its impact on power quality in relation to the new revised grid codes requirements. Furthermore, the concept can be used to study real-world related to power qualities in wind power system. In addition, the models can be expanded to include maximum power tracking and blade pitch controllers to meet other requirements of variable speed wind turbines. Therefore, the conclusion is that the wind farm installed with capacitors bank and fault current limiter can help a wind farm to ride-through a grid fault as seen from the different case studies simulated, without either rebuild of the existing system or implementation of any additional ride-through control setup in the nearby wind farm. To mitigate effects, the fault current limiters are used to enhance and enable other new technologies such as that, the electronic components of line commutated FACTS (HVDC \& PE-BC) are protected from nearby faults event since the model has been validated for grid codes in relation to power qualities.

\section{ACKNOWLEDGEMENT}

The author gratefully acknowledges the contributions of Smart Grid Laboratory (Yonsei University, Seoul, Korea) for PSCAD/EMTDC simulation software support for this work.

\section{REFERENCES}

Bollen M.J., Ribeiro P., Gu I.Y.H. and Duque C.A. (2010). Trends, challenges and opportunities in power quality research. Euro. Trans. Electr. Power,
20:

$3-18$.

https://doi.org/10.1002/etep.370

Duggan P.M. (2006). Integration Issues for Fault Current Limiters and Other New Technologies- a utility perspective. In Proc. 2006 IEEE Power Engineering Society General Meeting Conf.

Hansen A.D., Sorensen P., Janosi L., and Bech J. (2001). Wind farm modelling for power quality. In IECON IEEE Industrial Electronics Society 27th Annual Conf., 1959-1964.

Hansen A.D., Sorensen P., Blaabjerg F., and Becho J. (2002). Dynamic modelling of wind farm grid interaction, IEEE Trans. Wind Engineering, 26: 191-208. https://doi.org/10.1260/0309524023210 $\underline{39403}$

Ivan D., Lazaroiu G., Ungureanu G. and Udrea O. (2014). Influence on the power quality of the connection of wind power into the electricity grid transmission. In 16th International Conference on Harmonics and Quality of Power (ICHQP), Bucharest, 743-746. DOI: $10.1109 / \mathrm{ICHQP} .2014 .6842811$

Liang X. (2017). Emerging Power Quality Challenges Due to Integration of Renewable Energy Sources. In IEEE Transactions on Industry Applications, 53(2):

855-866.

DOI: $10.1109 /$ TIA.2016.2626253

Liu Q. and Li Y. (2020). An Inductive Filtering-Based Parallel Operating Transformer With Shared Filter for Power Quality Improvement of Wind Farm. In IEEE Transactions on Power Electronics, 35(9): 9281-9290. DOI: $10.1109 /$ tpel.2020.2973702

Marin R.C., Exposito A.G., Payan M.B. (2004). Wind Energy Integration in Distribution Networks: A VoltageStability Constrained Case Study. In Bulk Power System Dynamics and Control - VI, 2004 Conf., 577-582.

McCauley T., Pelfrey D. and Rottger W. (1980). The Impact of Shunt Capacitor Installations on Power Circuit Breaker 
Application. IEEE Trans. Power Apparatus and Systems. 6: 2210 2222. DOI:10.1109/TPAS.1980.319783

Mohammadi M., Moghani J.S., Ansari S.A., Milimonfared J. and Dehbashi A. (2018). Fuzzy logic based sensorless soft starter for constant frequency wind power plants. In 9th Annual Power Electronics, Drives Systems and Technologies Conference (PEDSTC), Tehran, 538-543.

Molinas M., Aresuul J., and Undeland T. (2008). Low Voltage Ride Through of Wind Farms With Cage Generators: STATCOM versus SVC, IEEE Trans. on Power Electronics, 23(3): 11041117. DOI: 10.1109/TPEL.2008.921169

Muljadi E., Butterfield C.P., Chacon J. and Romanowitz H. (2006). Power Quality Aspects in a Wind Power Plant. In Proc.
IEEE Power Engineering Society General Meeting Conf. DOI: 10.1109/PES.2006.1709244

Munteanu I., Bratcu A.I., Cutululis N.A. and Ceanga E. (2008). Optimal Control of Wind Energy Systems, vol. I. London: Springer-Verlag, 20.

Petru T. (2001). Modeling of Wind Turbines for Power System Studies. Licentiate thesis, Dept. Electric Power Eng., Chalmers University of Technology, Sweden.

Santoso S. (2009). Fundamental of electric power quality, vol. I. Texas: Scotts Valley, 162-168.

Santoso S. and Le H.T. (2006). Fundamental time-domain wind turbine models for wind power studies. IEEE Trans. Renewable Energy, 32: 24362452. doi:10.1016/j.renene.2006.12.008 